\title{
Uma cornucópia no Partenon: circuitos afetivos em uma vizinhança em Porto Alegre
}

Renan Giménez Azevedo ${ }^{1}$

Universidade Federal do Rio Grande do Sul

Resumo: A partir do conceito de circuitos (ZELIZER, 2009, 2011), esta etnografia trata das sociabilidades entre moradores de um conjunto habitacional em Porto Alegre, RS. O argumento central é que estas relações envolvem os sujeitos de diversas maneiras, circulando como moralidades, dinheiro, alimentos, bens, linguagens e outras formas que materializam e manifestam as afetividades. Esses circuitos afetivos, por sua vez, produzem e são produtos das políticas domésticas engendradas pelos envolvidos. Além disso, sugere-se que estes circuitos afetivos transbordam seus limites, sendo reconfigurados e agregando outros nexos às malhas sociais daquela vizinhança. Considera-se apropriado também que os frutos dessas moralidades sejam pensados enquanto assuntos de políticas domésticas, porque estão em constante negociação.

Palavras-chave: circuitos afetivos; afetos; economias morais; política doméstica.

${ }^{1}$ Doutorado em andamento no Programa de Pós-graduação em Antropologia Social (PPGAS/UFRGS). Mestre em Antropologia Social (UFRGS). Pesquisador associado ao Grupo de Antropologia da Economia e da Política (GAEP), ligado ao PPGAS/UFRGS. 


\title{
A cornucopia in the Parthenon: affective circuits in a neighborhood in Porto Alegre
}

\begin{abstract}
Based on the concept of circuits (ZELIZER, 2009, 2011), this ethnography deals with the sociability among residents of a housing complex in Porto Alegre, RS. The main argument is these relationships involve subjects in different ways, circulating the affections manifested as morals, money, food, goods, languages, and other forms. These affective circuits, in turn, produce and are products of domestic policies engendered by those involved. Furthermore, it suggests that these affective circuits, initially restricted to some residents in reciprocity, overflow their limits, being reconfigured and adding other links to the social networks of that neighborhood. It is also considered appropriate that the fruits of these moralities are thought of as matters of domestic policy, because they are in constant negotiation.
\end{abstract}

Keywords: affective circuits; affections; moral economy; domestic politics.

\section{Una cornucopia en el Partenón: circuitos afectivos en un barrio de Porto Alegre}

\begin{abstract}
Resumen: Basada en el concepto de circuitos (ZELIZER, 2009, 2011), esta etnografía trata de la sociabilidad entre los habitantes de un conjunto de moradas de Porto Alegre, RS. El argumento central es que estas relaciones involucran a los sujetos de diferentes formas, circulando como moralidades, dinero, comidas, bienes, lenguajes y otras formas que materializan y manifiestan afecto. Estos circuitos afectivos, a su vez, producen y son producto de las políticas hogareñas engendradas por los involucrados. Además, se sugiere que estos circuitos afectivos, inicialmente restringidos a algunos vecinos en reciprocidad, desborden sus límites, reconfigurando y sumando otros vínculos a las redes sociales de ese barrio. También se considera oportuno que los frutos de estas moralidades se conciban como asuntos de política hogareña, porque están en constante negociación.
\end{abstract}

Palabras clave: circuitos afectivos; afectos; ahorro moral; política hogareña. 
cornucópia (Datação: 1548)

1. Rubrica: mitologia. vaso em forma de chifre, com frutas e flores que dele extravasam profusamente, antigo símbolo da fertilidade, riqueza, abundância, e que, hoje, simboliza a agricultura e o comércio.

2. Derivação: por extensão de sentido. qualquer fonte de riqueza ou felicidade

(Dicionário Houaiss Eletrônico, 2009)

$\mathrm{D}$ estino este texto ${ }^{2}$ à análise dos circuitos de reciprocidade em um conjunto habitacional do bairro Partenon, em Porto Alegre, constituído em um terreno com trinta cabanas de madeira e administrado por uma empresa que oferece a locação destas moradias através de meios pouco burocráticos em comparação com o mercado imobiliário formal. Sugiro pensar nos moradores como pontos de convergência de vários afetos que circulam de forma dadivosa enquanto moralidades, dinheiro, alimentos, bens, linguagens e outras formas. Assim, o reconhecimento de um sujeito neste conjunto habitacional seria o resultado de sua participação em circuitos afetivos que, por sua vez, produzem e são produtos das políticas domésticas engendradas por moradores, visitantes e pela própria empresa.

Sobre o conceito de "circuito", me inspiro nas ideias de Viviana Zelizer (2009, 2011). O termo, bem como outros que a autora usa (pontes, encruzilhadas, laços), traz a noção de misturas presentes nas negociações, ou seja, que as trocas financeiras não são limitadas pela circulação de moeda, principalmente nas relações domésticas. Assim, os entrelaçamentos feitos pelas pessoas passam por uma série de cálculos das atividades, o que delimita as várias relações "por meio de práticas cotidianas, sustentando os laços por meio de atividades conjuntas, negociando constantemente o conteúdo exato destes laços sociais importantes" (ZELIZER, 2011: 37).

É necessário atentar que os circuitos são abordados por Zelizer (2009) em seu trabalho sobre moedas locais, ou seja, ela trata de formas monetárias de circulação restrita a uma região ou área, identificada por igrejas, cooperativas, feiras e outras comunidades. Quando invoco a ideia de circuitos afetivos, sugiro que há trânsitos de afecções e moralidades entre os sujeitos por meio destes circuitos. Ademais, uma pessoa pode estar em vários circuitos simultaneamente, compartilhando de vários tipos de afetividades. Afetar e ser afetado pelas palavras, ações, eventos, comidas, moralidades e tantos outros objetos em circulação significam entrar nos jogos em que tais dinâmicas estão presentes, recodificando as afecções de um tipo em outro, como seriam os casos de intercâmbios monetários que passam de um registro de trocas financeiros para dívidas morais. Meu argumento vai

2 Este trabalho é resultado da disciplina Seminários de Doutorado, destinada para abrir os horizontes teóricos de doutorandos do curso de Antropologia Social da UFRGS. Registro aqui meu profundo agradecimento ao professor Ruben George Oliven pela generosidade nas aulas, e a meus colegas pela parceria na jornada, com carinho especial à Angícia Mourão. 
nesta direção: demonstrar como as pessoas e os atores se envolvem pelos emaranhados da rede de reciprocidades desta vizinhança, podendo extrapolar os limites destas relações.

Também é necessário explicitar metodologicamente meu entendimento por "afetos". Esta é uma categoria que possibilita pensar os fluxos e a circulação de moralidades, dinheiro, alimentos, bens e linguagens entre os moradores. Da mesma forma que ser afetado autoriza a entrada em certos circuitos (FAVRETSAADA, 2005), também é uma postura analítica para o entendimento das éticas e moralidades presentes. Sobre este par, recupero a proposição que Didier Fassin (2018a) apresenta sobre moral, ou seja, os valores que compõem a "crença humana na possibilidade de diferenciar certo de errado" (FASSIN, 2018 ${ }^{\mathrm{a}}$ : 36). Ademais, quando moralidades de grupos de pessoas entram em atrito, resistência ou outras dinâmicas pelas negociações dos sujeitos, tais economias morais passam a ter uma dimensão política importante (FASSIN, 2018b; FASSIN e LÉZÉ, 2018): disputam-se bens, espaços, relacionamentos com pessoas, interpretações sobre eventos e demais interesses em jogo.

Ao mesmo tempo, também opero com a distinção entre moral e ética feita por Gilles Deleuze (2002). No caso, sua interpretação parte da obra de Spinoza, em que a moral opera no nível dos valores (e é, em certo sentido, transcendental), enquanto a ética é a existência imanente destes valores: "A moral é o julgamento de Deus [...]. Mas a Ética desarticula o sistema de julgamento. A oposição dos valores (Bem/Mal) é substituída pela diferença qualitativa dos modos de existência (bom/mal) (DELEUZE, 2002: 29)". Em síntese, proponho que as práticas (éticas) sejam orientadas por decisões morais e, como seus sujeitos estarão em constante negociação moral, as ações também possuem uma dimensão política. Estes circuitos afetivos envolveriam agentes e sujeitos nos mais diversos níveis: são éticas na medida em que possuem dimensões práticas que são manifestas pelas ações das pessoas; são imanentes em suas relações e posturas; e são moralidades, porque possibilitam o direcionamento para uma ou outra atitude, de acordo com uma série de valores que podem ser compartilhados ou não. Ao se afetarem pelas morais e éticas, as pessoas envolvidas nestes circuitos afetivos estariam jogando com as políticas domésticas daquele ambiente.

Como será visto no texto, muitos dos afetos são manifestos na forma de alimentos. Uma das razões pelas quais isto ocorre é pela intensa sociabilidade na cozinha. Desta forma, gostaria de retomar algumas questões sobre como pensar as relações a partir da alimentação. Não é minha intenção observar como diferentes objetos e alimentos são fonte para classificação e ordenamento das sociabilidades ou de outras categorias êmicas, ou seja, busco algo diferente da proposta de Lévi-Strauss (2010). Encaro estes objetos e alimentos como as materialidades por meio das quais as performances dos circuitos ocorrem. Este argumento é fundamentado nas discussões de agenciamentos mercantis (CALLON, 2013, 2016), segundo as quais os mercados podem ser analisados a partir das mercadorias negociadas e pela passivatividade3 destes bens, uma vez que podem ser funções ora passivas (controláveis e previsíveis), ora ativas (instigam, tomam parte e causam ações) nos circuitos mercantis (CALLON, 2013, 2016). Deste modo, os agenciamentos mercantis tratam bens e serviços como processos que articulam os diversos campos e planos por meio deles e não sobre eles. Assim, sugiro que estes objetos e artefatos constituam os circuitos afetivos na vizinhança aqui estudada.

${ }^{3}$ Callon propõe observar a simultânea atividade e passividade dos bens no mercado, cunhando o termo passiv(ac)tion, no qual eu traduzo como passivatividade. 
As afecções de pessoas e outros seres que estão além de certos circuitos, a ponto de reconfigurar a rede de relações por romper com os limites aparentes, podem ser pensados no que chamarei de "transbordamentos". Para pensar esta ideia, tomo como mote o argumento de Tim Ingold (2019: 141): "como um nexo de vida e crescimento dentro de uma malha de relações, o organismo não é limitado pela pele. Ele, também, vaza”. A proposta que apresento é a de que as relações sociais não podem ser contidas por uma membrana, um limite, muros ou qualquer coisa que o valha. Ao contrário, por estarem em fluxos constantes, os seres nestas malhas relacionais estão presentes a cada novo contato, a cada nova troca. Sendo assim, tomo por hipótese que estas rupturas seriam "transbordamentos": um volume muito grande de relações que não podem ser contidas naqueles circuitos, sendo rompidas e reestruturadas por conta da convolução produzida.

Os transbordamentos forneceriam material para emaranhamentos nas relações entre habitantes do condomínio e outras pessoas. As afinidades entre alguns moradores, ao formarem circuitos afetivos entre si, podem limitar outros indivíduos naquele circuito específico - mas uma ruptura pode transbordar as moralidades em jogo e trazer mais sujeitos para compartilhar daquela gramática. Isto não significa que os indivíduos estejam obrigatoriamente sob a força da coletividade, pois uma pessoa pode fazer-se reservada para alguns circuitos e participar de outros. Contudo, é possível pensar nas variações das relações entre moradores, de maior ou menor autonomia, se forem considerados em quantos e em quais circuitos afetivos alguém se insere. Nas próximas seções, explicarei como se manifestam estas circulações morais nas diversas camadas que as envolvem, partindo do que seria o aspecto mais amplo, o condomínio e o terreno como um todo, passando pelas sociabilidades na cozinha, ambiente de uso comum, até chegar nas dinâmicas mais específicas dos eventos sociais que acontecem no local.

Minhas reflexões partirão de minha própria vivência enquanto residente no conjunto habitacional cujas circunstâncias locais buscarei descrever. Como bem aponta Hélio Silva (2009: 176), "Acordos e mal-entendidos, tessituras sociais por excelência, termos com os quais nos referimos às interações, sejam diálogos, cooperações ou competições, são propriedades sociais que impregnam o processo etnográfico". Assim sendo, avisei informalmente à vizinhança deste trabalho, dizendo que "É uma pesquisa para uma disciplina do doutorado" e fornecendo mais detalhes conforme a curiosidade surgia. Desta forma, tomei notas, conversei, participei e atuei nos vários circuitos ao longo de três meses, pensando sobre como outros moradores entravam nas sociabilidades do condomínio fechado das cabanas.

No momento em que redijo este texto, há vinte e duas unidades alugadas das trinta disponíveis. Este número variou bastante entre janeiro e agosto de 2020, com um vale de 9 habitantes e pico de 29 pessoas pouco antes do início do isolamento social. Algumas destas pessoas são mais presentes no cotidiano, então escolhi quatro figuras centrais para meu trabalho: Aminata, Estevão, Hela e Ícaro. Logo no começo desta etnografia, conversei com eles, perguntei se autorizavam usá-los neste texto e, com resposta afirmativa, alterei seus nomes por outros sugeridos por eles mesmos para preservar suas identidades. Assim, buscarei construir os argumentos tendo como alicerce os dados de campo colhidos no período. 


\section{Conhecendo o condomínio}

Por se tratar de uma série de relações que ocorrem em uma vizinhança habitacional fechada, que trato como um condomínio, preciso mapear o terreno onde as unidades habitacionais (cabanas de madeira) estão construídas. Desta forma, sugiro que estas dinâmicas seriam estabelecidas pela forma que os alojamentos estão dispostos. Neste terreno em específico, as cabanas que estão disponíveis para habitação são uma peça (um quarto) com um banheiro individual. Para alugar uma unidade, é necessário contatar a empresa que administra o local e apresentar um comprovante de renda e um contrato de trabalho ou um comprovante de matrícula, indicando que a pessoa trabalha ou estuda. É possível firmar contratos de diversas temporalidades (mensal, semestral ou anual) com diferentes valores (maior o tempo de contrato, menor o valor do aluguel mensal). Nos custos, estão inclusos consumo de luz, água, internet, limpeza das áreas comuns e manutenção do mobiliário e das instalações. Como havia comentado no início, trinta "cabaninhas" de madeira com banheiro próprio estão disponíveis para habitação, de modo que a cozinha e a lavanderia são espaços de uso comum.

Pela forma da construção, a cozinha torna-se um local onde os moradores se encontram ao prepararem suas refeições. Por esta razão, argumento que a cozinha é um espaço de sociabilidades entre moradores, cujas relações sociais são azeitadas constantemente durante o preparo dos alimentos, podendo extrapolar as paredes daquela peça. Na Figura 1 está um croqui da planta do terreno, onde é possível observar como as cabanas estão dispostas, além da localização da cozinha.

Figura 1: Diagrama das cabanas (não em escala). Fonte: elaborado pelo autor.

\begin{tabular}{|c|c|c|c|c|c|c|c|c|c|c|}
\hline 30 & & 29 & 28 & 27 & 26 & 25 & 24 & 23 & 22 & $\begin{array}{c}N \\
N \\
\text { s. }\end{array}$ \\
\hline \multirow{4}{*}{$\begin{array}{l}\text { Churras- } \\
\text { queira }\end{array}$} & \multicolumn{10}{|c|}{ Circulação } \\
\hline & \multirow{2}{*}{ 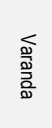 } & \multirow{2}{*}{ 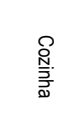 } & 16 & 17 & 18 & 19 & 20 & 21 & & \multirow{2}{*}{ Lavanderia } \\
\hline & & & 15 & 14 & 13 & 12 & 11 & 10 & & \\
\hline & \multicolumn{9}{|c|}{ Circulação } & \\
\hline 1 & & 2 & 3 & 4 & 5 & 6 & 7 & 8 & 9 & \\
\hline
\end{tabular}

Podemos observar que, durante a construção, buscou-se alguma simetria para a melhor alocação das cabanas, de modo que dezoito alojamentos estão dispostos na parte mais externa, junto aos muros limítrofes, enquanto as outras doze estão no meio do terreno. Assim, cada "cabaninha" tem sua própria vizinhança e isso confere alguma privacidade a seu morador, diante de eventuais visitantes e outros habitantes. Na entrada está a cozinha e, aos fundos, a lavanderia, os dois locais de uso comum dos moradores. Por ter sido construída de frente para o portão de entrada, a cozinha torna-se um local para a recepção de visitantes e moradores chegadiços, o que fornece mais uma camada de privacidade nas habitações.

Da mesma forma que a planta do terreno, a cozinha também é organizada de forma simétrica. Nela estão dispostas três geladeiras para todos os moradores, 30 
armários numerados (um para cada cabana), um micro-ondas, duas mesas-bancadas fixas nas paredes, duas pias e dois fogões. Sob as pias, encontram-se panelas, talheres, potes e louças para uso comunitário, mas há moradores que têm seus próprios utensílios nos armários. Cada morador também deve ter sua própria esponja e detergente para lavar louças, costumeiramente também guardadas nos armários junto com temperos, sal, açúcar, outros objetos e comidas dos cotidianos domésticos. Estas orientações a respeito dos produtos de limpeza, bem como o respeito aos bens de outras pessoas, estão expostas em cartazes fixados nas paredes e geladeiras.

O horário de maior movimentação costuma ser após as $18 \mathrm{~h}$. O perfil de moradores é variado, mas todas as pessoas estudam e/ou trabalham. Por conta disto, a rotina faz com que a cozinha esteja vazia ao longo do dia, exceto no horário de almoço, em que alguns fazem sua refeição em casa. Depois que o Sol se põe, os moradores voltam de seus trabalhos e suas aulas, carregando sacolas de compras dos supermercados das redondezas, com pães, leite, carnes e frutas. Neste momento a cozinha ganha vida: colegas comentam sobre seus dias, desabafando as frustrações e compartilhando as felicidades; geladeiras são abertas para acomodar perecíveis, enquanto certos produtos que já estavam guardados são questionados por “Alguém sabe de quem é isso aqui?"; potes e panelas são manuseados para o preparo das refeições, tilintando sobre as pias e fogões. Também é o momento em que desentendimentos por morar coletivamente surgem, em que louças sujas e comidas estragadas, cujo fedor infestam o lugar, motivam tais discussões. Apesar dos confrontos, o que poderia virar uma agressiva cacofonia costuma ser um harmonioso aconchego depois de um árduo dia de trabalho daqueles desconhecidos familiares.

A cozinha também é estendida para a varanda. Depois que foi embora, um antigo morador deixou sua mesa para os seus vizinhos. O móvel fica na varanda, sendo utilizada para diversos fins: jogar baralho e jogos de tabuleiro, assistir televisão, conversar e, inclusive, fazer as refeições. Por conta desta mesa ficar na varanda, é comum o anúncio de que se vai "comer fora". Em sua origem, a expressão é uma alusão a sair de casa, da residência, para ir a um restaurante. Entre os moradores, e em tempos de isolamento social, "comer fora" é sinônimo de usar a mesinha na varanda para alguma refeição. No fim da tarde, marcado pelas 18 horas, é comum que alguém decida "comer fora" e outras pessoas sentem-se juntas e em volta da mesinha, seja para jantar, seja para simplesmente ficar conversando com os vizinhos ali presentes.

Por meio da mesinha, a cozinha ultrapassa suas paredes de madeira. $\mathrm{O}$ mesmo ocorre com a "churrasqueira" - um latão cortado pela metade, em formato de meia lua, apoiado em um suporte de metal -, ela também estende os limites da cozinha para além da varanda. O meio-tambor foi adquirido pelos próprios moradores, por iniciativa de Estevão, que bancou a compra da churrasqueira em uma ferragem próxima. A decisão de comprar a "churrasqueira" surgiu do interesse em comum dos moradores para fazer jantas e comemorações, mas a encomenda daquele bem veio de Estevão justamente por ele ser o assador. Antes de ele se mudar para o nosso condomínio, em uma visita para conhecer a habitação, ele viu que existia uma "churrasqueira" de modelo semelhante - tambor de latão cortado ao meio -, embora estivesse enferrujada e com o fundo caído pelas intempéries de sol, chuva e carvão. Foi, então, essa peça que fez com que ele decidisse se mudar para o nosso condomínio. Esta estrutura de latão foi adquirida por moradores anteriores e não pela empresa mantenedora, ou seja, consertos e 
substituições deveriam partir de residentes. Para dividir o valor da nova "churrasqueira", Estevão fixou em uma das geladeiras um papel com o preço da compra e uma lista de nomes daqueles que já haviam contribuído com o ressarcimento. Quando questionado sobre o que aconteceria se entregassem um montante maior que o pago na "churrasqueira", Estevão é categórico em explicar que aquele dinheiro seria destinado para o próximo evento dos moradores.

A aquisição de bens para uso comunitário, como o caso da churrasqueira, é uma tática comum entre residentes. Há alguns eletrodomésticos de uso restrito e outros de uso comum. De forma semelhante a Estevão, Hela é outro morador que mobiliza tais compras. Antes de eu chegar, ele e outras pessoas fizeram a compra de um liquidificador, que fica guardado e é de uso restrito àqueles que contribuíram para a "vaquinha" (coleta de dinheiro) daquele eletrodoméstico. Ele fez uso da mesma tática para a compra de uma sanduicheira elétrica para uso coletivo. Junto ao cupom fiscal de compra que ele havia fixado na porta de uma das geladeiras, eu escrevi um recado que avisava que aquele aparelho era "nosso" (de todos os moradores) e que deveríamos cuidar e mantê-lo limpo para que seu uso fosse duradouro. Neste mesmo recado, fiz referência a outras carcaças de torradeiras elétricas e as razões pelas quais elas estavam inutilizadas - fios derretidos, chapas sujas, poeira e gordura acumulada. Apesar disso, não é estranho encontrar restos de pão na torradeira e, quando Hela encontra o aparelho limpo, ele fala em tom irônico "Isso é tão emocionante que vou até chorar".

Observando as relações com mesas, "churrasqueiras" e sanduicheiras, é possível notar alguns pontos de articulação na cozinha. Ainda que as pessoas se reúnam naquele ambiente por conta dos alimentos, os objetos e mobiliários são nodos relacionais sobre os quais moradores e visitantes se apoiam para lidar uns com os outros e com as refeições. Neste sentido, encaro estes objetos como um efeito das relações prévias dos habitantes das cabanas, sendo manifestações destes desejos de comensalidade. Seja como for, "churrasqueiras" e outros utensílios também podem ser vistos como materiais por onde as afetividades circulam e se manifestam, dinamizando os circuitos econômicos das "cabaninhas".

A partir destes utensílios de uso comum, adquiridos pelos moradores ou não, regras tácitas costumam ser acordadas e seguidas. Existem as normas manifestas pelos contratos e pelos cartazes espalhados pelo condomínio, onde são regulamentados tópicos como horários de funcionamento de equipamento ou de ocupação de espaços, valores e multas, bem como são proibidas atividades como fumar nas dependências de uso comum e o furto de alimentos. Ainda que existam as câmeras de vigilância, elas não significam que todas estas regras serão cumpridas. Assim, o cumprimento ou não dessas regras e a consideração de sua legitimidade podem ser motivos de disputas entre os residentes, e vizinhos de condomínio, e a empresa que gerencia o local. Estas regras tácitas ficam evidenciadas, portanto, quando há disputas e comenta-se que seu acordo nunca foi feito, apenas espera-se que outros moradores agirão de uma certa forma. Na seção seguinte, exploro essas políticas domésticas no ambiente mais movimentado do condomínio, a cozinha.

\section{Dinâmicas na cozinha}

Por conta da construção do terreno, e pela ausência de uma área de convivência, a cozinha é o ambiente de sociabilidade por excelência neste condomínio. A inexistência de uma área projetada para o convívio social é tema de queixa interna, mas também é usado para justificar a ocupação da cozinha em momentos 
de confraternização. Em sua etnografia em uma cozinha comunitária, Helisa de Castro (2016: 280-1) sugere que aquele ambiente seria "onde as vidas estão interconectadas, [...] um local onde se desenvolvem laços, afetos e desafetos. Embora dentro dela não se estabeleçam somente relações harmônicas, é lá que pessoas convivem e socializam". Trazendo tais ideias para o contexto em que escrevo, partirei minhas análises sobre a limpeza, tema de constante atrito entre moradores, pois são justamente as negociações morais e tácitas sobre a higiene da cozinha os temas de constante afecção de sujeitos.

Ao entrar na cozinha de manhã cedo, é possível encontrar panelas com óleo de fritura nos fogões, louça de molho dentro das pias, farelos sobre as bancadas. Isto ocorre por conta dos diversos hábitos e horários alimentares e de trabalho dos moradores. Logo antes das jornadas de trabalho e de estudos, a cozinha se enche com café e pães, com alguns moradores comendo nas bancadas ou à mesa e outros voltando para a privacidade de suas cabanas. Nestes períodos, a louça deixada por outras pessoas é posta de lado, ao mesmo tempo em que novos resíduos aparecem sem qualquer identificação de autoria. A menos que algum utensílio esteja ocupado com restos de comida e alguém precise utilizar aquele objeto imediatamente, como panelas de uso comum, ninguém se responsabiliza pela louça deixada por terceiros.

Para mitigar os problemas no uso de materiais comuns, alguns moradores possuem utensílios de cozinha apenas seus. Assim, há uma distinção entre os bens de uso comum e os bens particulares. Os primeiros são panelas, pratos, talheres e potes que estão dispostos junto às pias, para que qualquer pessoa pegue, use, limpe e coloque de volta ao local. Já os bens particulares são utensílios do mesmo tipo que os bens comuns, mas estão alocados nos armários de metal, podendo ser trancados com cadeados individuais e ter seu acesso restrito. Também é possível ver moradores transitando com seus objetos entre suas cabanas e a cozinha.

Os armários individuais na cozinha são pequenos, o que demanda boas habilidades para acomodar os utensílios, e as geladeiras também possuem um espaço que deve ser ocupado tendo em mente o uso que outros moradores farão. Em cima dos armários, podem ser vistos potes e caixas organizadoras com coisas que não couberam no espaço originalmente destinado a elas. Nas geladeiras, alguns potes e embalagens de alimentos são identificados com numeração ou por algum recipiente especial, normalmente potes com tampa para armazenar alimentos. Seja como for, os moradores procuram ocupar um espaço na geladeira, e o seu local é o que identifica o proprietário daquela comida. A respeito disso, Aminata comentou uma tática: "Se você tirar um pote, coloque um copo ou uma garrafa no lugar pra saberem que tem alguém ali”. Desta forma, quem precisar ocupar um espaço na geladeira terá que lidar com outras coisas e remanejar a organização para não atrapalhar demais usuários daquele eletrodoméstico. Imagino que, por esta razão, certos moradores optam por deixar suas guarnições nas "cabaninhas" - não ter que lidar com materiais de terceiros seria uma forma de mitigar atritos com a vizinhança, seja pela limpeza da cozinha, seja em disputas por espaço no local.

Por conta dos trânsitos entre casa e cozinha, é normal encontrar potes com feijão de molho, bandejas de carne descongelando sobre as pias e até mesmo garrafas de óleo e pacotes de pão sobre as bancadas. Também é comum encontrar fogões acesos, com panelas em fervura, sem ninguém na cozinha - e podemos deduzir que, provavelmente, a/o cozinheiro/a está lavando roupa ou fazendo alguma outra tarefa doméstica. Como há uma proibição velada sobre não mexer 
nas coisas de terceiros, ninguém faz questão de guardar aqueles objetos ou apagar as chamas do fogão. Se há preocupação com as chamas, moradores perguntam uns aos outros “de quem é aquela panela fervendo?”. Mas os produtos sobre mesas e bancadas são empurrados para o lado, abrindo espaço para o uso do móvel.

As negociações sobre como e onde armazenar alimentos também se misturam com os arranjos a respeito da limpeza, o que fica evidente quando se observa que alimentos de desconhecidos em cima da bancada também não são manuseados ao mesmo tempo em que a sujeira na louça de terceiros não é tocada por moradores. Nas janelas acima das pias, estão penduradas sacolas de supermercados do bairro para serem utilizadas como lixeiras. Da mesma forma que compras nas bancadas, alimentos cozendo no fogão e bens nos armários e nas geladeiras, é comum testemunhar uma proliferação de sacolinhas de lixo cheias penduradas na cozinha. $\mathrm{O}$ acordo tácito é fechar a sacola de lixo quando a encontrar cheia e depositar o saco na lixeira externa para que a pessoa responsável pela limpeza (uma funcionária da administradora das cabanas) faça o descarte apropriado.

A limpeza é um tema de riso e decepção entre alguns moradores, pois encontrar a cozinha com várias sacolas de lixo abertas é motivo de conjecturas das razões daquilo acontecer. Certa vez, Estevão e eu estávamos fechando as sacolas e fazendo sarro com quem utiliza das sacolas, mas não recolhe o lixo. Eu argumentei que “deve ser algo difícil! Precisa de curso da NASA!”, e Estevão respondeu que "o cara deve ter medo de perder uma das bolas, porque deve achar que isso é coisa de mulher". Noutro momento, Ícaro foi categórico e acusou uma "falta de capricho" daquelas pessoas: "Isso vem de casa. Minha mãe sempre me ensinou a ser cuidadoso com as coisas, ser limpo e caprichoso". Aminata levantou a hipótese de que "pode cair a mão". Nestas declarações podem ser vistas as diversas categorias críticas a este outro imaginado, percebido como alguém sem inteligência, sujo, sem educação doméstica, um homem de masculinidade frágil. Hela também contribuiu com seu ponto de vista: "São pessoas que não se veem no lugar dos outros e esperam que alguém faça esse tipo de trabalho no seu lugar”. Para aprofundar esta questão, é necessário explorar a composição da vizinhança, onde moram quatro mulheres e dezoito homens. Boa parte é de residentes temporários: pousam em suas cabanas apenas nos dias úteis e retornam a suas famílias nos finais de semana e feriados, ou que pretendem ficar no condomínio por menos de um ano. Considerando que a maioria destes residentes temporários é formada por homens, especulamos que eles seriam estes "outros" que deixam as coisas sujas na expectativa de que outros limpem. Ou seja, é suposto que sejam pessoas que venham de um ambiente com papeis de gênero bem demarcados, em que a casa seria responsabilidade estritamente da mulher, como se aponta na crítica específica de Estevão. Mais uma vez, moralidades se misturam e entram em atrito nestes circuitos, onde a acusação de desleixo com o ambiente - e, no limite, com demais moradores - se torna uma das questões em disputa.

Além das disputas pelo espaço nas geladeiras e armários e da busca pela limpeza, também existem os jogos para uso da cozinha. Ainda que a peça seja ampla, o local foi pensado para uso de apenas duas pessoas, quatro no máximo (se pensarmos em casais), como é evidenciada na mobília: dois fogões, duas pias, duas bancadas. E por ser um ambiente de uso temporário, não há cadeiras, apenas banquetas de plástico. Contudo, estas expectativas não se cumprem nos momentos de grande movimento. Se o ditado "em coração de mãe sempre cabe mais um" pudesse ser atualizado, substituiria o músculo cardíaco materno pela cozinha deste condomínio fechado de "cabaninhas". No horário de almoço dos finais de 
semana, já testemunhei uma dúzia de pessoas no ambiente (eu no meio, inclusive). As atividades são variadas: gente encerrando a refeição e lavando louça para guardar; pessoas cozinhando nas panelas; fornos sendo pré-aquecidos para os bolos que serão assados; compras recém-chegadas sendo lavadas e guardadas; temperos cruzando; pratos sendo alcançados; micro-ondas apitando, alimentos alocados no congelador; alguém ouvindo música; várias conversas atravessadas; e alguma outra alma comendo alguma coisa na bancada.

Por conta das circulações que tornam a cozinha claustrofóbica, os corpos dos moradores giram, desviam, dão passos para frente e para trás, dançando uma dança que ninguém havia ensaiado. Há antecipação de gentileza pelos presentes que abrem e seguram portas, liberam espaços nas pias e nas bancadas, alcançam produtos e utensílios que serão usados. Ouvem-se poucos pedidos de licença, mas é possível ouvir várias desculpas e muitos agradecimentos. Na cozinha lotada, ou até mesmo com poucas pessoas, os corpos tentam passar despercebidos ou, pelo menos, causar o mínimo de incômodo possível.

A presença e a ausência de pessoas na cozinha indicam um contraste interessante: de um lado, os lixos e as louças sujas se acumulam e ficam visíveis quando o ambiente está vazio, com especulações de quem deixa a sujeira; por outro lado, quando a cozinha está movimentada e cheia de vida, com muita circulação de pessoas, a sujeira some. Dado tal cenário, penso que os descartes que constituem o lixo estariam vinculados a uma dissolução de laços, uma vez que, na cozinha animada, tudo e todos estão envolvidos e emaranhados.

\section{Laços que se manifestam e transbordam}

Ao longo do texto, procurei demonstrar formas por meio das quais algumas moralidades são mobilizadas nos circuitos domésticos deste condomínio e tornam-se visíveis pela mediação de utensílios, alimentos, descartes, eletrodomésticos, móveis e corpos dos moradores. Entretanto, os exemplos que trouxe ainda estão muito contidos em negociações instantâneas. Nesta seção, busco compreender como estas relações emaranhadas transbordam afetividades, possibilitando outros nexos para circuitos de economias morais. Para tal, tomo como base as refeições coletivas, eventos constantes que fornecem um bom repertório para pensar tais temas e onde os transbordamentos ocorrem. Como exemplo, trago as churrascadas.

A empresa mantenedora do condomínio não construiu uma churrasqueira. Entretanto, este não foi um problema para os condôminos. Como já comentei, Estevão tomou a iniciativa de comprar uma "churrasqueira", pagando o aparato no próprio cartão de crédito e, depois, dividindo o valor entre os moradores interessados e informando em uma folha o preço e os nomes de quem havia se comprometido. Assim como tantas outras obrigações, há uma regra tácita para uso da churrasqueira: limpá-la depois de usar. Isso implica eliminar as cinzas do carvão, organizar os espetos e virar o latão para que sua abertura fique para baixo, evitando o acúmulo de água no caso de chuva.

O evento da churrascada tem seu ápice quando os alimentos são postos para assar. Antes disso, o planejamento envolve principalmente quem tem interesse na atividade e passa por um transbordamento em que se abre o circuito agregando outros moradores que queiram participar do evento. Às vezes, alguma dívida é quitada para a compra do que será consumido. A partir do rol de partici- 
pantes, define-se um cardápio de que o assador deverá se ocupar. Se houver outras comidas a serem preparadas fora da churrasqueira, os responsáveis delas se ocuparão na cozinha.

Figura 2: "Churrasqueira" em uso. Fonte: Acervo do autor.

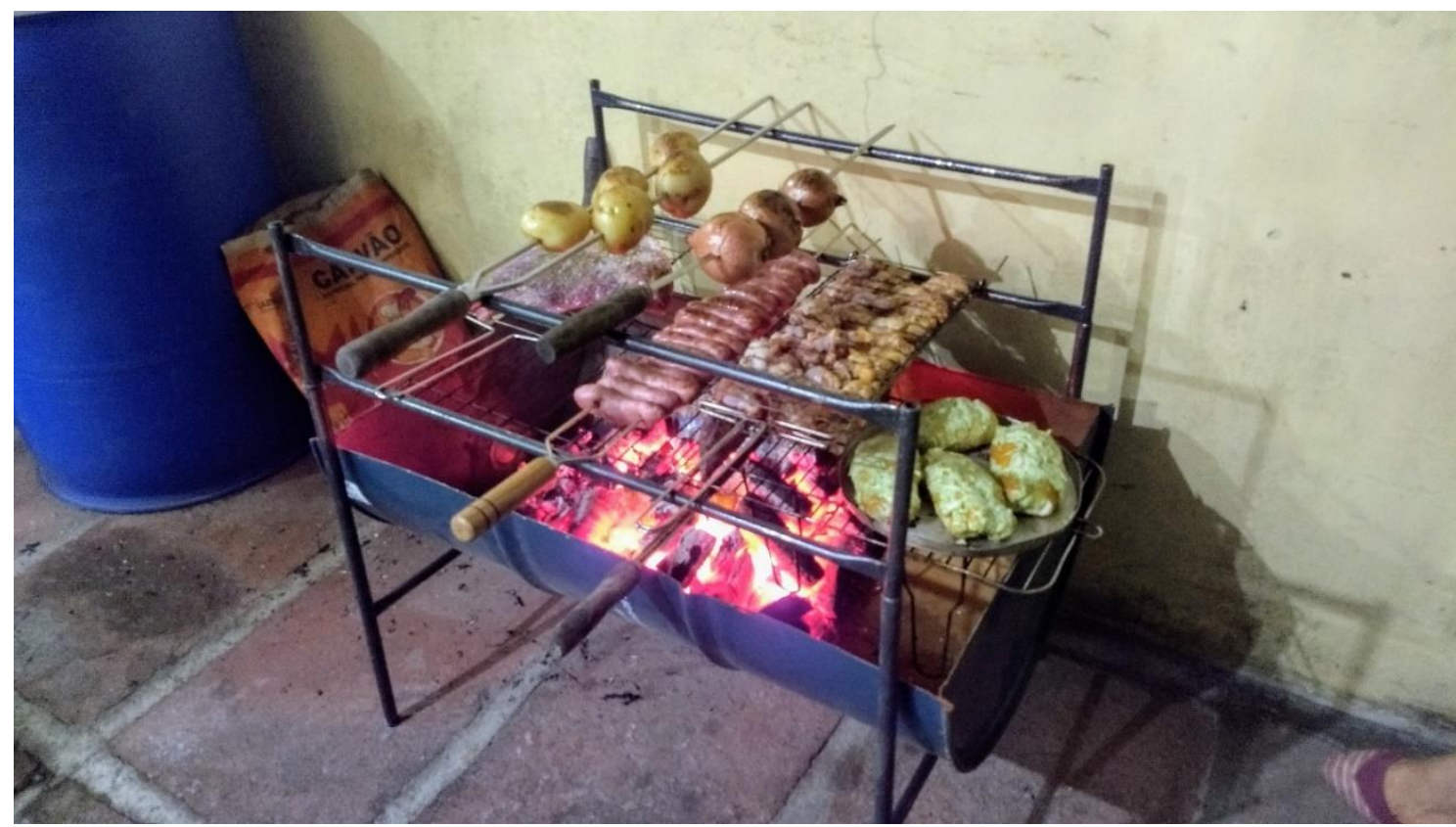

Na Figura 2 acima, podemos ver que, além das carnes (vazio, salsichão e frango), há batatas, cebolas e pães com um recheio cremoso caseiro. Estes são uma invenção de Hela, que batizou o alimento de "tartaruga" por conta da aparência que lembra um réptil. Trata-se de um substituto do pão de alho, em que o recheio cremoso é feito a partir de uma receita de maionese caseira, preparada e incrementada com temperos por Hela. O preparo deste molho e da "tartaruga" são anteriores à colocação das carnes na churrasqueira. Os tubérculos e os bulbos, por sua vez, são postos para assar pouco antes das carnes. Como Aminata é vegetariana, as cebolas, as batatas e a "tartaruga" são preparadas para ela. Eventualmente, ela contribui com outros acompanhamentos, tais como vinagrete ou salada de maionese. Estevão, que é o assador costumeiro, faz malabarismos com as grelhas e os espetos para que nenhum alimento queime, aproximando-o ou afastando-o das chamas.

Da mesma forma que várias comidas com tempos de preparo diferentes são dispostas simultaneamente na churrasqueira, várias pessoas com diversas moralidades estão naquele circuito. As preferências gastronômicas da vegetariana são distintas daquelas dos carnívoros Estevão, Hela e demais participantes, mas as dinâmicas do preparo e do consumo incluem todos os envolvidos. Caso outros grupos de residentes decidam fazer um churrasco, seus cálculos poderão excluir o grupo de Aminata, Estevão e Hela, seja por questões de afinidade, seja por qualquer outra justificativa. Noutros termos, quem não entrar no jogo é sumariamente desconsiderado naquele circuito. $\mathrm{O}$ que importa nestes movimentos é que a churrasqueira, bem como outros móveis e utensílios, pode ser pensada como 
um catalisador de relações, manifestando circuitos afetivos na medida em que demanda um planejamento para seu uso.

Os preparativos de um evento como uma churrascada são concentrados para a compra dos insumos, tais como alimentos e bebidas, produtos para higiene e limpeza e o próprio carvão. No açougue, Estevão costuma ir acompanhado com mais alguém (Hela, eu ou outros vizinhos) para ajudar a carregar as compras e para já fazer a divisão do pagamento. O montante da compra é dividido pelo número de presentes e alguma dívida pode ser quitada neste momento, com negociações espontâneas: "Deixa que eu pago a tua parte, pois estou te devendo este mesmo valor”. Após a confraternização, é contabilizada a parte que cabe a cada participante. Os cupons fiscais e outros comprovantes de pagamento são fixados na geladeira, junto a uma folha em que consta o total das compras e a divisão per capta, além de uma lista dos nomes ao lado dos quais se pode-se colocar um "Ok" para indicar cada pagamento realizado. Como exemplo, trago o caso de um final de semana em que aconteceram dois eventos, uma pastelada e um churrasco, e o grande fiador foi Estevão (conforme indicado na Figura 3).

Figura 3: "Contabilidade" dos pasteis e do churrasco. Fonte: Acervo do autor.

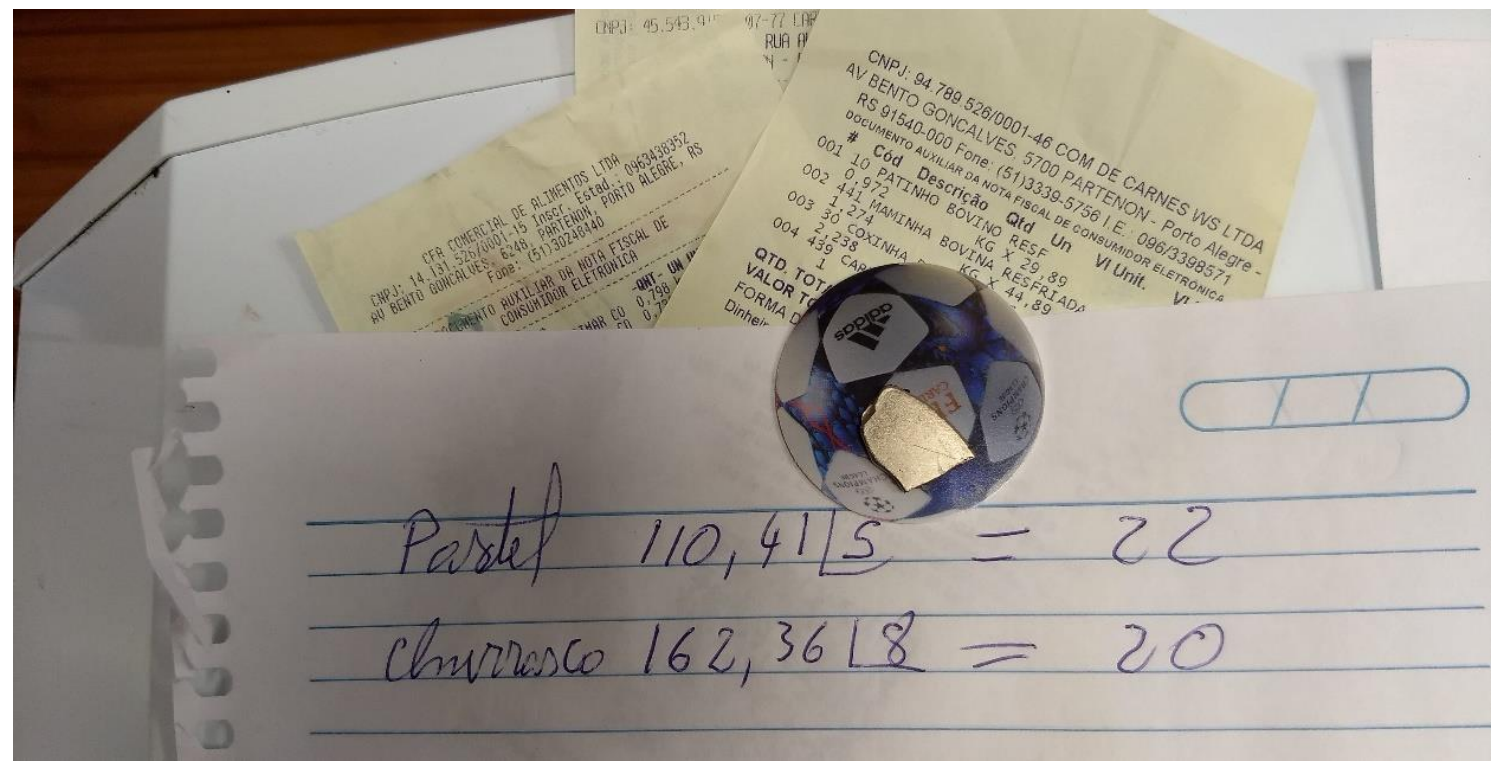

Como podemos ver, as compras referentes àquelas notas fiscais foram feitas para duas refeições distintas, com números de participantes diferentes. A pastelada ocorreu na sexta e o churrasco no sábado daquele final de semana. No domingo, foram feitos dois arrozes de carreteiro, um com o guisado não usado para recheio dos pasteis e outro com as sobras do churrasco. Os "carreteiros", porém, não foram incluídos na contabilidade, pois o arroz e os demais ingredientes foram adquiridos anteriormente e eram de estoques pessoais dos moradores. A divisão dos montantes, por sua vez, não foi exata. Estevão ficaria em falta de R \$ 2,77 das compras, mais sua mão-de-obra como assador que também não é contabilizada. Justamente nestas variações presentes em trocos não retribuídos e trabalhos não remunerados é que os circuitos passam a ser constituídos. Enquanto as dádivas 
ficarem em um constante estado de suspensão de modo que as contrapartidas não sejam quitadas de imediato, as relações continuarão aquecidas e, da mesma forma que um braseiro na churrasqueira, devem ser trabalhadas para que continuem acesas.

Concluído o evento, passamos à limpeza das áreas comuns e, mais uma vez, os participantes dançam uma coreografia sem música enquanto se deslocam na cozinha. Por ser assador, Estevão assume a responsabilidade pela limpeza da churrasqueira e dos espetos, enquanto outras pessoas cuidam dos utensílios de uso comum, como tábuas de corte e travessas. As carnes são colocadas em bandejas e formas de metal para serem guardadas nas geladeiras, outros alimentos são igualmente alocados no eletrodoméstico. Logo que as cinzas esfriam, elas são colocadas no saco de carvão, já habitado por latas de cerveja vazias. O tambor da churrasqueira é virado com a abertura para baixo e os espetos colocados sobre todo o aparato. De acordo com Estevão, a forma mais apropriada de guardar espetos é com eles sujos de gordura, para evitar a ferrugem. Quanto às louças, cada morador lava seus próprios pratos e talheres. "Assim como irmãos, cada um lava o seu", argumenta Aminata.

Caso alguém não participe de um circuito ou de um evento, seus efeitos também podem ser moralmente qualificados. As agradáveis músicas e conversas durante uma churrascada se tornam ruídos incômodos para quem não está envolvido naquela atividade, principalmente quando estão além do horário de silêncio (demarcado pelas 22 horas). A praticidade de colocar uma mesa na cozinha para que vários possam comer sem recorrer às bancadas é um obstáculo para quem busca acessar os armários, as geladeiras, os fogões e até mesmo as pias. No caso da limpeza, a escolha por não dispensar o óleo usado para fritar algum bife e reutilizá-lo no dia seguinte é objeto de desagrado das pessoas que rejeitam tal prática (ainda que a compreendam), apontando a proliferação de moscas e a eventual chateação daqueles que gostariam de utilizar a panela quando, naquele momento, está ocupada sem estar em uso. Estas disputas são resolvidas em negociações imediatas, perceptíveis em frases como "Podem baixar o volume?" e "Desculpe, vou liberar aqui para ti”. A repetição destas situações pode gerar outros mal-estares, reforçando os circuitos já constituídos para que os outros imaginados como fonte destes conflitos não sejam incluídos.

Os circuitos de relações e trocas também se manifestam na resistência de alguém em fazer parte das dinâmicas. Desta forma, o contraste entre aqueles que estão dentro ou fora de certos circuitos é o que possibilita perceber tais moralidades. Ícaro é alguém bastante reservado e que evita participar destes eventos junto aos demais moradores. Perguntei-lhe a razão desta postura e ele me apresentou uma série de justificativas que, em suma, dizem respeito ao fato de ter um perfil diferente dos demais moradores-participantes dos eventos: como alguém mais velho (único com mais de 50 anos no condomínio), seus gostos e assuntos não são os mesmos da vizinhança. Além disso, Ícaro me disse que é alguém que prefere não ficar falando de sua vida com outras pessoas e está constantemente usando fones de ouvido escutando alguma banda de metal em um volume bem alto. Ele também argumenta com seu trabalho de segurança noturno e seus horários, em particular os de sono à tarde. Assim, o que seria considerado almoço é praticamente sua janta. Em contraste, Hela e Ícaro brincam bastante, fazendo piadas provocativas e conversando sobre um amplo leque de assuntos. Apesar de ser reservado, Ícaro é bastante cordial com outros residentes e procura manter uma posição neutra em relação aos outros moradores. 
Algumas das formas de circuitos de reciprocidade destes moradores são todas estas configurações, com atritos e fluidez, em que as disputas de espaço se tornam negociações e atividades conjuntas, com manifestações a favor e negativas de inserção. As relações constituídas na vizinhança também transbordam os muros. Restos de comida não são simplesmente descartados - ao contrário, são preparados para que outros sujeitos possam se nutrir destes. Cascas de ovos, borras de café e erva-mate de chimarrão viram adubos para as plantas locais; farelos de pães e torradas são arremessados para que os passarinhos possam bicar; e ossos e carnes dos churrascos tornam-se banquetes para os cães da matilha da redondeza. A respeito dos cachorros, aliás, há outras afetividades em jogo, como nas compras pensadas nos animais. Aminata, por exemplo, já trouxe pacotes de petiscos e ração para dar aos cães. Estevão, por sua vez, tem o costume de comprar uma porção a mais de mortadela justamente para ofertar a estes "vizinhos". E Ícaro, tão reservado, também compartilha dos alimentos com a "cuscaiada" após as refeições.

As dinâmicas com os animais, assim como os humanos residentes nas "cabaninhas", também expressam circuitos afetivos, inclusive com disputas manifestas nos sacos de lixo que são descartados. Três vezes por semana, a pessoa responsável pela limpeza nas áreas comuns fecha as sacolas com lixo acumulado pelos moradores a cada dois dias, sempre em quantidades volumosas. Junto com descartes de higiene pessoal, nas sacolas há restos de comida ou embalagens de alimentos congelados, chamando a atenção da matilha que acaba rasgando os lixos e sujando as calçadas. Da forma semelhante às negociações para a convivência entre os moradores, pequenos litígios a respeito de limpeza e espaço ocorrem na calçada com os cães. Mais uma vez, os circuitos se rompem e transbordam, sendo transformados em novos circuitos que misturam outros afetos e moralidades.

\section{Circuitos afetivos e políticas domésticas}

Ao longo deste artigo, procurei demonstrar como as sociabilidades domésticas e de vizinhança são desenvolvidas pelos moradores deste conjunto habitacional. Tais relações ocorrem em diversas instâncias, com destaque nas esferas alimentares, higiênicas e financeiras, com temáticas e profundidades que variam conforme os circuitos em que as pessoas se inserem. Estes múltiplos laços são reorganizados pelos agentes e sujeitos por conta dos circuitos, que podem ser interrompidos, bifurcados e vinculados pelos vários acontecimentos que ali ocorrem, entre disputas e concordâncias, desentendimentos e concertos. Para fins de conclusão, gostaria de apontar para possíveis desdobramentos para uma antropologia das políticas domésticas, justificando o conceito de circuitos afetivos como uma ferramenta analítica nesta etnografia.

As convivências amistosas nesta vizinhança não são compulsórias, mas o simples fato de conviver mais ou menos com os vizinhos já coloca os moradores em algum circuito de afetos. Um bom exemplo que ilustra a situação é a construção de um outro imaginado e incapaz de fechar as sacolas de lixo. Quem não compartilha destas ou daquelas normas tácitas é este outro em potencial. Na medida em que tais regras são frutos de moralidades - uma vez que são é esperado o cumprimento daquilo que se acredita ser certo em detrimento do errado -, as atividades desempenhadas tornam-se as chicanes ${ }^{4}$ dos circuitos afetivos, canalizando o fluxo de interações.

4 No automobilismo, cada uma das grades e das proteções que circundam os circuitos, sinalizando trajetos para quem está pilotando, recebem o nome de chicane. 
É apropriado que os frutos das moralidades de moradores sejam pensados enquanto assuntos de políticas domésticas, porque estão em constante negociação entre os agentes envolvidos. Os tensionamentos e relaxamentos, como aqueles vistos nas regras (tácitas ou explícitas) de convivência, pautam as discussões e os eventos da vizinhança, estabelecendo novas afetividades que, por sua vez, produzem novos circuitos afetivos. Portanto, sugiro que a vivência doméstica entre moradores é uma experiência política e que pode ser mensurada e observada pelos circuitos que vinculam e separam indivíduos.

As malhas afetivas desta vizinhança de cabanas são produtos de constantes reviravoltas das reciprocidades de todos que se envolvem. Mesmo alguém que seja completamente isolado das relações está na iminência de ser afetado. Tais relações não se esgotam e acabam produzindo mais e mais circuitos, a ponto de ultrapassar seus próprios limites. Assim como uma cornucópia, o mitológico símbolo da abundância, estas afecções estão transbordando o tempo todo, agregando novas dinâmicas a cada dia que passa, sem nunca esgotar o repertório de possibilidades. É nesse sentido que também posso considerar que o conceito de vazamento seja útil para pensar uma antropologia ecológica, mas apresenta algumas limitações para pensar este caso dos moradores das cabanas. A razão é simples: ainda que possam ser expandidos, os circuitos de economias morais são fechados, de modo que quem não compartilha daquelas moralidades não experienciará os espaços da mesma forma que aqueles que estão inseridos na malha de relações. Por se tratar de relações dadivosas que atravessam as temporalidades e as espacialidades, tais circuitos podem ser rompidos em algum ponto, criando nexos para si, ou seja, afetando e integrando novos sujeitos nestas economias morais.

Recebido em 21 de setembro de 2020.

Aprovado em 19 de novembro de 2020.

\section{Referências}

CALLON, M. Qu'est-ce qu'un agencement marchand? In: CALLON, M.; AKRICH, M.; RABEHARISOA, V.; GRANDCLÉMENT, C.; MÉADEL, C.; MALLARD, A.; LATOUR, B.; MUNIESA, F.; HENNION, A.; DUBUISSON-QUELLIER, S. (org.). Sociologie des agencements marchands. Paris: Presses des Mines via OpenEdition, 2013. p. 325-440.

. Revisiting marketization: from interface-markets to market-agencements. Consumption Markets \& Culture, v. 19, (1): p. 17-37, 2016.

CASTRO, H. C. DE. Gostos, regras e significados à mesa e ao fogão: situações etnográficas em uma cozinha comunitária. In: URIARTE, U. M.; MACIEL, M. E. (org.). Patrimônio, cidades e memória social. Salvador: EDUFBA, 2016. p. 279300.

DICIONÁRIO Houaiss Eletrônico. 3. ed. São Paulo: Objetiva, 2009 
DELEUZE, G. Espinosa. São Paulo: Escuta, 2002.

FASSIN, D. "Além do bem e do mal? Questionando o desconforto antropológico com a moral". In: RIFIOTIS, Theophilos; SEGATA, Jean (orgs.). Políticas etnográficas no campo da moral. Porto Alegre: Editora da UFRGS, 2018a. pp. 3550.

FASSIN, D. "Economias morais revisitadas". In: RIFIOTIS, T.; SEGATA, J. (orgs.). Políticas etnográficas no campo da moral. Porto Alegre: Editora UFRGS/ABA Publicações, 2018b. pp. 51-87.

FASSIN, D.; LÉZÉ, S. (org.). A questão moral. Campinas: Editora da Unicamp, 2018.

FAVRET-SAADA, J. Ser afetado. Cadernos de Campo, 13 (13): 155-161, 2005.

INGOLD, T. Estar vivo. Petrópolis: Vozes, 2019.

LÉVI-STRAUSS, C. O cru e o cozido. 2. ed. São Paulo: Cosac Naify, 2010.

SILVA, H. R. S. A situação etnográfica: andar e ver. Horizontes Antropológicos, 15 (32): 171-188, 2009.

ZELIZER, V. A. R. Dualidades perigosas. Mana, 15 (1): 237-256, 2009.

ZELIZER, V. A. R. A negociação da intimidade. Petrópolis: Vozes, 2011. 
A Aceno recebe em resenhas,

ensaios fotográficos,

REVISTA DE ANTROPOLOGIA DO CENTRO-OESTE dossiês (propostas). ISSN : $2358-5587$ Iteressados pareceristas

podem realizar seus cadastros no site 